\title{
Synthesis and Characterization of Co/Ni/CoNi-ZSM-5 Catalyst for Hydrogen Production
}

\author{
Widayat Widayat ${ }^{1,2^{*}}$, Arianti Nuur Annisa ${ }^{1}$, Hantoro Satriadi ${ }^{1}$ and Syaiful Syaiful ${ }^{3}$ \\ ${ }^{1}$ Department of Chemical Engineering, Faculty of Engineering, Diponegoro University, Semarang \\ ${ }^{2}$ Laboratory of Material Technology, Centre of Research and Service Diponegoro University, Semarang \\ ${ }^{3}$ Department of Mechanical Engineering, Faculty of Engineering, Diponegoro University, Semarang
}

\begin{abstract}
Nickel is commonly used as a catalyst in hydrogen production. However, the use of nickel catalysts in the steam reforming process has the disadvantage of coke formation and high cost. Therefore, in this research, Ni/ZSM-5 catalyst synthesis was used to reduce production cost and an addition of cobalt (Co) metal to avoid coke formation. The method consists of a synthesis of ZSM-5 catalyst using hydrothermal process. Furthermore, the crystalline product was impregnated with the metal cobalt, nickel and combination of cobalt-nickel as much as $2 \%$ by weight metal/weight of the catalyst. Then the XRD and EDX characterization of Co/ZSM-5, $\mathrm{Ni} / Z S M-5$, and CoNi/ZSM-5 was done followed by catalytic testing in the production of hydrogen from glycerol using steam reforming process. From XRD characterization results showed that Co/ZSM- 5 catalyst has a crystallinity of $78.69 \%$, Ni/ZSM- 5 catalyst has $70.04 \%$ crystallinity and CoNi/ZSM-5 catalyst has $76.99 \%$ crystallinity. Catalytic testing on hydrogen production showed that CoNi/ZSM-5 catalyst produced the highest hydrogen concentration of $1,756.33 \mathrm{ppm}$ while $\mathrm{Ni} / Z \mathrm{SM}-5$ catalyst produces $1,240 \mathrm{ppm}$ and Co/ZSM-5 catalyst produces $491 \mathrm{ppm}$.
\end{abstract}

\section{Introduction}

The increased world economy was accompanied by increased energy consumption, especially fuel. During this time the fuel used is sourced from petroleum which cannot be renewed. By the increase of energy consumption, there is depletion of petroleum reserves. Therefore, the fuel was produced using renewable raw materials derived from plant or animal oil. On the other hand, the use of renewable energy produces lower pollution and environmentally friendly. Biodiesel is one of the most mass-produced renewable energy. Sales of biodiesel have increased rapidly in 2014 from 14.2 billion tons in 2008 to 29.1 billion tons [1]. In the production of biodiesel produced glycerol as by product. The production of $10 \mathrm{~kg}$ biodiesel can produce $1 \mathrm{~kg}$ of glycerol or $10 \%$ by weight [2], so by increasing production of biodiesel the amount of glycerol product also increases.

Glycerol is a versatile compound which can be used as a raw material for producing other derivative compounds. Industries that use glycerol as raw materials are food and beverages, personal care, oral care and tobacco [3]. At this time began to develop the use of glycerol to produce new energy. Hydrogen is one of the most widely used compounds in industry and as a fuel with $95 \%$ of hydrogen production using fossil raw materials. By the increasing amount of glycerol, it used as raw materials in hydrogen production. Steam reforming is one of the most widely used processes in hydrogen production [4]. The production of hydrogen by steam reforming process produces the highest number of moles of hydrogen $[5,6]$.

In hydrogen production, the commonly used catalyst is alumina, but alumina catalyst $\left(\mathrm{Al}_{2} \mathrm{O}_{3}\right)$ has a thermal deterioration that is unstable at high temperatures [7]. The process of hydrogen production that is widely applied in the industry is steam reforming using high temperature. Therefore, the use of zeolite catalysts is preferred because it has micropore structure, high area, high thermal stability and high $\mathrm{CO}_{2}$ affinity. In addition, the ZSM-5 catalyst is stable at high temperatures $\left(1000^{\circ} \mathrm{C}\right)$ and at low $\mathrm{pH}(\mathrm{pH}=3)$, so it is appropriately used in the steam reforming process [8]. However, a zeolite is a non-metallic mining product, so its availability is limited. In addition, the composition of natural zeolite varies so that its properties and characteristics not optimal if used as a catalyst [9]. By knowing this it is necessary to make the synthesis of zeolite.

Zeolite type is quite diverse, ZSM-5 is one type of zeolite which is often used as a catalyst [8]. The ZSM-5 catalyst synthesis (Zeolite Socony Mobil-5) was first performed by Argauer and Landolt patented by Mobil Oil Corporation in 1972 [10]. The ZSM-5 catalyst can be used to produce various products through a catalytic

Corresponding author: widayat@live.undip.ac.id 
cracking process. The type of product which produced by ZSM-5 catalyst was influenced by the physical and catalytic properties of the constituent material. Some parameters that may affect the nature of the ZSM-5 catalyst include the silica and alumina sources, the template and the crystallization conditions [11], so that in the preparation of ZSM-5 catalysts can be modified according to the desired product type.

Based on Pastor-Pérez and Sepúlveda-Escribano [4] research, the use of $\mathrm{NiSn} 30 \mathrm{CeO}_{2} / \mathrm{C}$ catalyst on GSR process is capable of producing the best hydrogen yield of $47 \%$. The presence of Ni metal is capable of breaking the $\mathrm{C}-\mathrm{C}$ bond on glycerol thereby increasing the yield of hydrogen produced. Zamzuri et al. [12] and Yurdakul et al. [13] performed hydrogen production using a combination of $\mathrm{Al}_{2} \mathrm{O}_{3}, \mathrm{ZrO}_{2}, \mathrm{La}_{2} \mathrm{O}_{3}$, olivine, $\mathrm{SiO}_{2}$ and $\mathrm{MgO}$ catalysts. In their research used catalyst support in the form of metal $\mathrm{Ni}$ and $\mathrm{Pd}$. The highest hydrogen selectivity was $86 \%$ using $\mathrm{Ni} / \mathrm{Al}_{2} \mathrm{O}_{3}$ catalyst at a temperature condition of $692^{\circ} \mathrm{C}$ [12]. In the Yurdakul et al. [13] research, the highest yield was $74 \%$ using $\mathrm{Ni}$ $\mathrm{Pd} / \mathrm{Al}_{2} \mathrm{O}_{3}-\mathrm{ZrO}_{2}$ catalyst at operating temperature $800^{\circ} \mathrm{C}$.

In this research, the synthesis of ZSM-5 catalyst was done using hydrothermal process. Furthermore, ZSM-5 synthesis was impregnated using metals to produce hydrogen. Hydrogen production will be done through steam reforming process. The metal support to be used is metal cobalt $(\mathrm{Co})$ and nickel $(\mathrm{Ni})$. This is because the metal is easy to obtain, cheap and activated at steam reforming operating temperature at $4500^{\circ} \mathrm{C}-800^{\circ} \mathrm{C}$ $[14,15]$.

\section{Materials and methods}

\subsection{Materials}

The materials used were $\mathrm{KAl}\left(\mathrm{SO}_{4}\right)_{2} \cdot 12 \mathrm{H}_{2} \mathrm{O}$ (for analysis, Merck), $\mathrm{H}_{2} \mathrm{SO}_{4}$ (98\%, Merck), $\mathrm{Na}_{2} \mathrm{SiO}_{3}$ (extra pure, Merck), $\mathrm{NaOH}$ (for analysis, Merck), $\mathrm{Ni}\left(\mathrm{NO}_{3}\right)_{2} \cdot 6 \mathrm{H}_{2} \mathrm{O}$ (for analysis, Merck) and $\mathrm{Co}\left(\mathrm{NO}_{3}\right)_{2} \cdot 6 \mathrm{H}_{2} \mathrm{O}$ (for analysis, Merck). Glycerol 98\% was purchased from Indrasari chemical store. Nitrogen gas $\left(\mathrm{N}_{2}\right)$ with $99.9 \%$ purity was purchased from PT. Samator Gas. Distilled water was provided by Membrane Research Centre Laboratory, CORES-DU.

\subsection{Catalyst synthesis}

The catalyst synthesis was performed based on the Latourette et al. [16] and Widayat and Annisa method [17]. The procedure of making catalyst is done by making solution A by mixing $\mathrm{KAl}\left(\mathrm{SO}_{4}\right)_{2} .12 \mathrm{H}_{2} \mathrm{O}, \mathrm{H}_{2} \mathrm{SO}_{4}$ and $\mathrm{H}_{2} \mathrm{O}$. Then the A solution was mixed with sodium silicate to homogeneous. Then $40 \% \mathrm{NaOH}$ solution was added and homogenized. Molar ratio of mixed solution are $0.056 \mathrm{KAl}\left(\mathrm{SO}_{4}\right)_{2} .12 \mathrm{H}_{2} \mathrm{O}: 0.57 \mathrm{H}_{2} \mathrm{SO}_{4}: 11.5 \mathrm{H}_{2} \mathrm{O}$ : $3.5 \mathrm{Na}_{2} \mathrm{SiO}_{3}: 1.4 \mathrm{NaOH}$.

The catalyst feedstock mixture was crystallized using a hydrothermal system with 8 hours and 24 hours crystallization time and crystallization temperature $90^{\circ} \mathrm{C}$, $120^{\circ} \mathrm{C}$ and $150^{\circ} \mathrm{C}$. After the crystallization process is complete, the crystal product was cooled to room temperature for 24 hours. Next, the crystal product was washed using distilled water and followed by filtration. The crystal product was dried using an oven at $110^{\circ} \mathrm{C}$ for 12 hours. Then the crystal was calcined at $600^{\circ} \mathrm{C}$ for 5 hours.

\subsection{Catalyst impregnation}

The impregnation of the catalyst is carried out by using nickel metal (Ni), cobalt (Co) and nickel and cobalt metal alloys. The impregnation was carried out by adding $2 \%$ weight metal/weight catalyst. The impregnation process was carried out at $60^{\circ} \mathrm{C}$ and stirred for 6 hours, then stays for 48 hours. Furthermore, the filtration process was done followed by catalyst drying at $110^{\circ} \mathrm{C}$ for 6 hours. Then the catalyst was calcined at $600^{\circ} \mathrm{C}$ for 5 hours with nitrogen gas.

\subsection{Catalyst characterization}

The ZSM-5 crystal product was characterized by composition analysis and crystallinity analysis. The crystallinity analysis was performed using X-Ray Diffractometer, XRD-7000S type, Shimadzu brand with $\mathrm{Cu}$-targeted tube $\mathrm{X}$-ray tube, $30 \mathrm{kV}, 30 \mathrm{~mA}$ and $\mathrm{K} \alpha$ radiation. The XRD analysis results data was processed by using software PCXRD and PDF4 + . The catalyst composition was analysed using Energy Dispersive XRay Fluorescence Spectrometers, EDX-7000 type, Shimadzu brand. The process of catalyst characterization was done in the Diponegoro University Integrated Laboratory.

\subsection{Hydrogen production}

Hydrogen production was carried out by a steam reforming process using a fixed bed reactor. The procedure is to load the catalyst by filling the centre reactor with 2 grams of catalyst. Then a glass wool was added as a catalyst holder. Loading feed is done by filling vaporizer vessel with a feed consisting of glycerol and water at a ratio of 1: 9 of $1000 \mathrm{ml}$. Evaporation of the feed was carried out at a temperature of $180^{\circ} \mathrm{C}$. Then steam feed that has been formed is driven by the flow of nitrogen gas to the reactor with an operating temperature of $500^{\circ} \mathrm{C}$. The hydrogen production process was carried out for 10 minutes. The gas product was streamed online to the hydrogen sensor and gas analyser. In addition, a portion of the gas was accommodated for analysing the composition using Gas Chromatography Mass Spectrometry (GCMS). The steam reforming instrument was showed in Figure 1. 


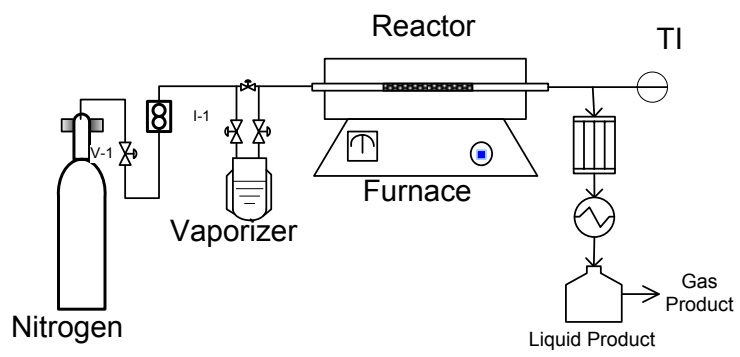

Fig. 1. Steam reforming instrument (dimension of reactor: inside diameter $=1,5 \mathrm{~cm}$; outside diameter $=2,0 \mathrm{~cm}$; thickness of catalyst $=2 \mathrm{~cm}$ )

The product from the steam reforming process of glycerol comprises liquid and gas products. The liquid product was analysed using High Performance Liquid Chromatography (HPLC) to determine the composition of glycerol in the product. The gas product was analysed using an online hydrogen sensor for 10 minutes to determine the amount of hydrogen gas produced. Then in the early and final minutes of the gas product were analysed online by using a gas analyser to know the composition of by products in the form of $\mathrm{CO}, \mathrm{CO}_{2}$ and hydrocarbon gas. Meanwhile, to know the type of hydrocarbon gas produced was analysed by using Gas Chromatography Mass Spectrometry (GCMS) on the gas product that has been accommodated.

\section{Result and discussion}

\subsection{Catalyst synthesis and characterization}

\subsubsection{XRD Analysis}

The crystallization process of ZSM-5 catalyst synthesis was carried out for 8 hours at $200^{\circ} \mathrm{C}$. The catalyst product obtained was characterized using X-Ray Diffractometer (XRD) to determine the structure and composition of the catalyst. Diffractogram of XRD analysis results was showed in Figure 2.

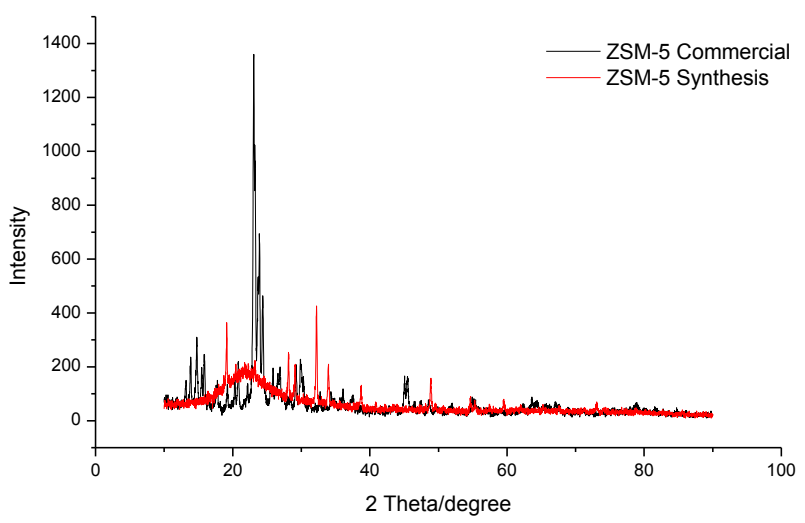

Fig. 2. ZSM-5 diffractograms

From the XRD difractogram shows there is a difference between ZSM-5 synthesis and commercial ZSM-5. ZSM-5 synthesis has the highest peak at $2019^{\circ}$; $28^{\circ}$ and $32^{\circ}$, but the commercial ZSM-5 has the highest peak at $2 \theta 13^{\circ} ; 23^{\circ}$ and $45^{\circ}$. However, ZSM-5 synthesis also has a peak at $13^{\circ} ; 23^{\circ}$ and $45^{\circ}$ with low intensity. Peak at 2 theta $23^{\circ}$ can be increased by adding the concentration of $\mathrm{NaOH}$ solution [18]. The crystallinity of ZSM-5 synthesis is $44.09 \%$ and the commercial ZSM-5 has a crystallinity of $76.06 \%$. This is because ZSM-5 synthesis has an amorphous crystal structure so the degree of crystallinity is low [19].

The ZSM-5 catalyst was impregnated using cobalt and nickel metal. The impregnated catalyst were analysed using XRD and EDX. XRD Diffractogram was showed in Figure 3.
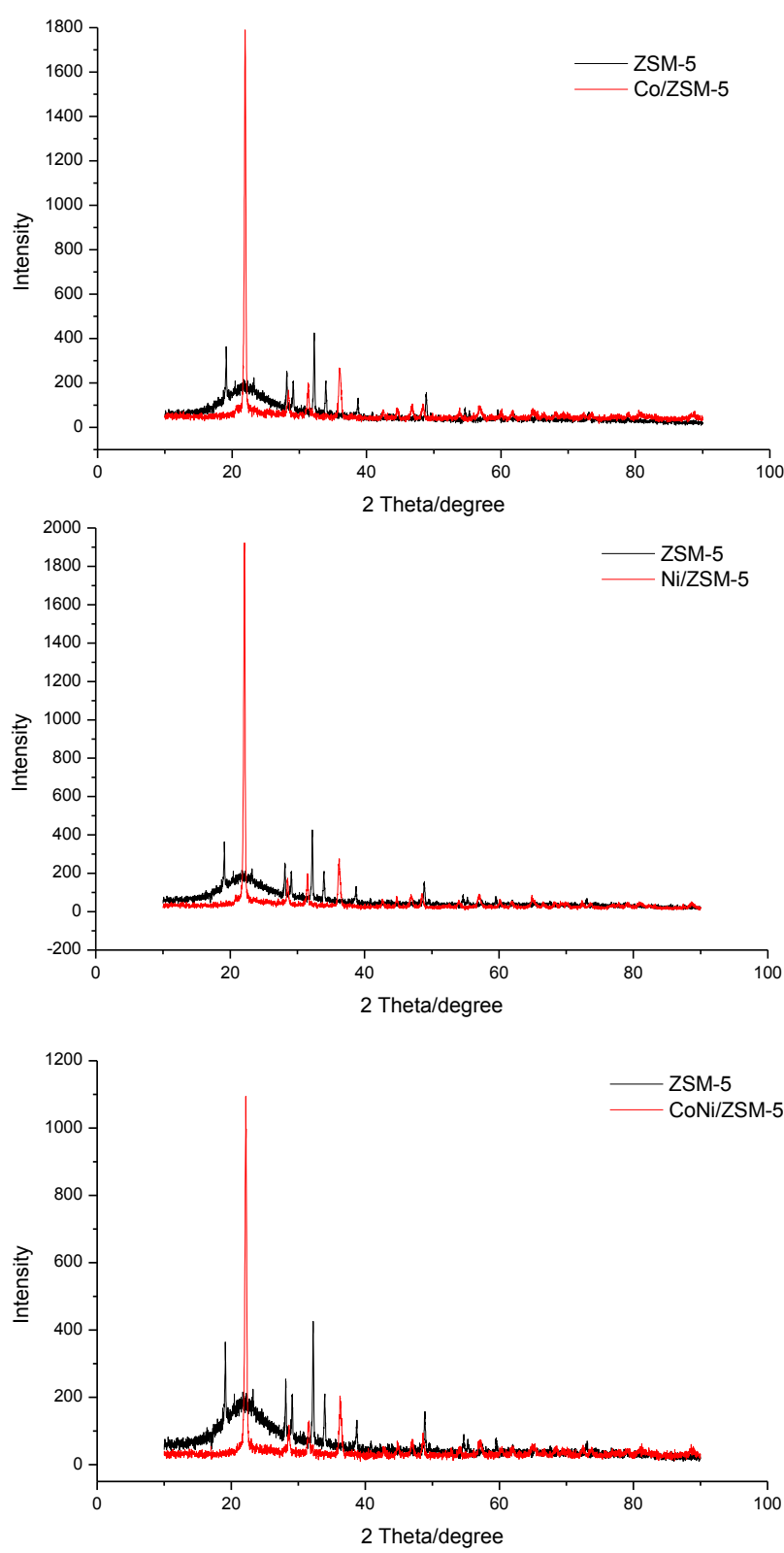

Fig. 3. XRD diffractograms of Co/ZSM-5, Ni/ZSM-5 and CoNi/ZSM-5

From Figure 3 shows that the impregnated catalyst has a higher intensity than ZSM-5 synthesis. Co/ZSM-5, $\mathrm{Ni} / \mathrm{ZSM}-5$ and $\mathrm{CoNi} / \mathrm{ZSM}-5$ were recalcined at $600^{\circ} \mathrm{C}$. Crystallinity of Co/ZSM-5; Ni/ZSM-5 and CoNi/ZSM-5 were $78.69 \% ; 70.03 \%$ and $76.98 \%$. Calcination can reduce catalyst impurities and increase crystal formation, so the crystallinity of the impregnated catalyst becomes increases. 


\subsubsection{EDX Analysis}

The catalysts were characterized using EDX to know the metals composition. Figure 4 and Table 1 were showed the EDX analysis result.
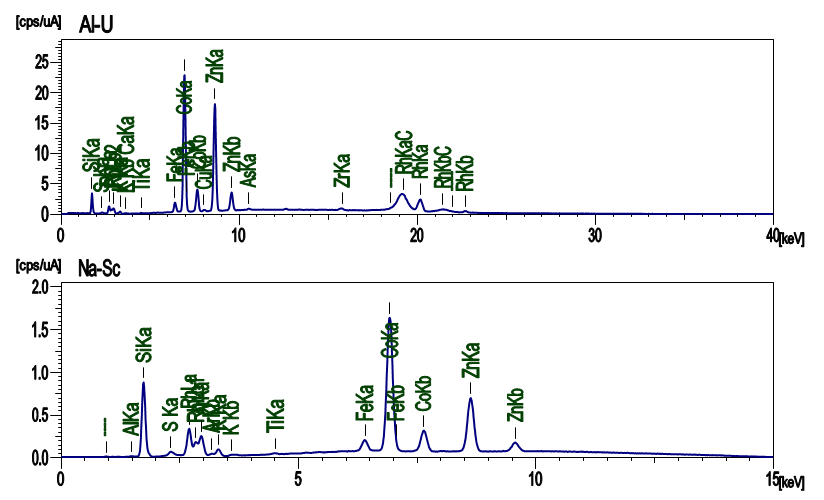

a. Co/ZSM-5
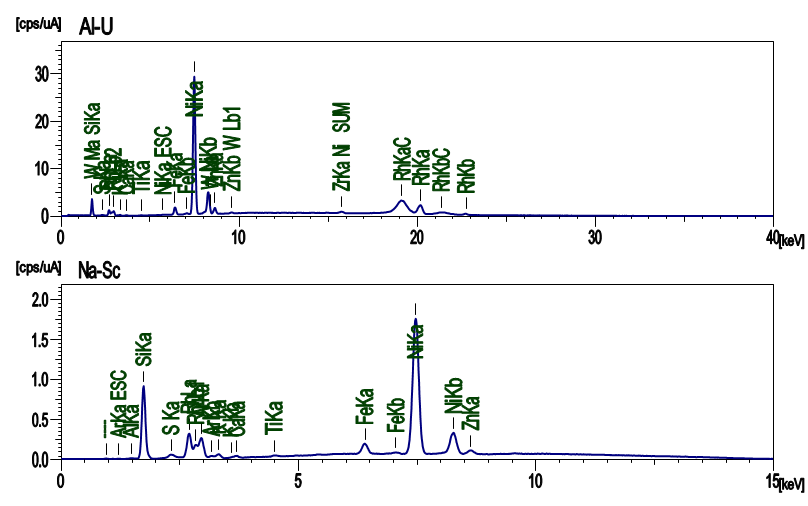

b. Ni/ZSM-5
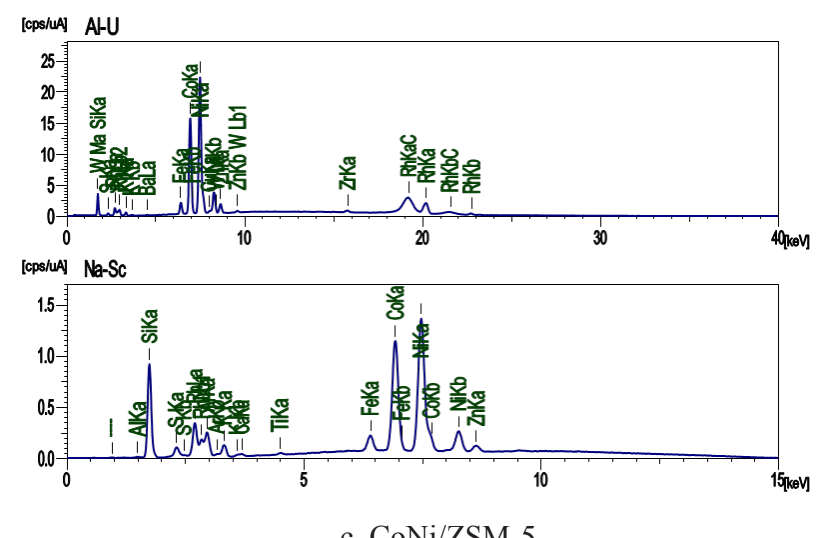

c. $\mathrm{CoNi} / \mathrm{ZSM}-5$

Fig. 4. EDX analysis result

Table 1. Metals compound in impregnated catalyst

\begin{tabular}{|c|c|c|}
\hline Catalyst & $\begin{array}{c}\text { Metals } \\
\text { Compound }\end{array}$ & Result \\
\hline Co/ZSM-5 & $\mathrm{Co}_{2} \mathrm{O}_{3}$ & $1.472 \%$ \\
\hline $\mathrm{Ni} / Z \mathrm{ZSM}-5$ & $\mathrm{NiO}$ & $1.335 \%$ \\
\hline \multirow{2}{*}{ CoNi/ZSM-5 } & $\mathrm{Co}_{2} \mathrm{O}_{3}$ & $1.041 \%$ \\
\cline { 2 - 3 } & $\mathrm{NiO}$ & $0.935 \%$ \\
\hline
\end{tabular}

From EDX analysis result shows that the metals did not totally attach in the catalyst surface. It caused by the low interaction between metals and support due to imprecise calcining temperatures [20]. The cobalt oxide and nickel oxide compounds formed are caused by an imperfect reduction process at the time of calcination.

\subsection{Hydrogen production}

The catalysts were used to produce hydrogen gas using glycerol feedstock. The gas product is analysed using a hydrogen sensor to know the hydrogen yield and gas sensor to known composition of other gas products. From the analysis showed that the catalyst can produce hydrogen, carbon monoxide, carbon dioxide and hydrocarbon gas product. Figure 5, 6 and 7 below are shows the product composition.

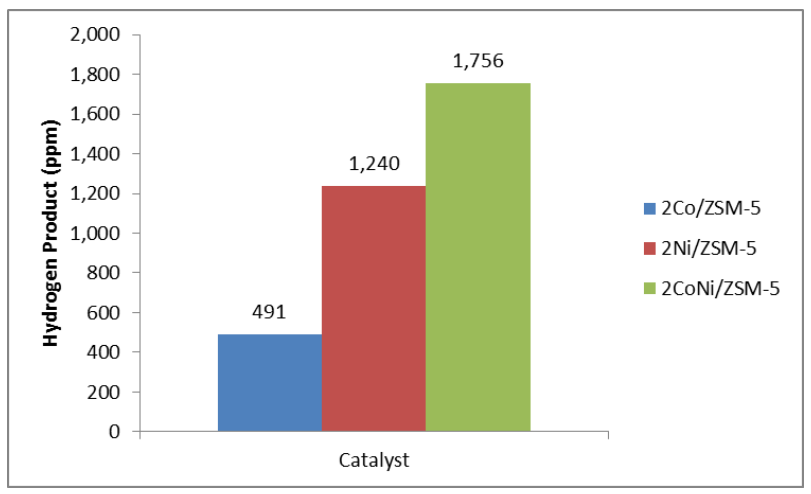

Figure 5. Hydrogen product

The highest hydrogen product obtained was 1756 ppm using CoNi/ZSM-5 catalyst. The Co/ZSM-5 catalyst produced $491 \mathrm{ppm}$ hydrogen and Ni/ZSM-5 catalyst produced $1240 \mathrm{ppm}$. The impregnation of cobalt and nickel metal on the ZSM-5 catalyst can increase the activity of the catalyst. The hydrogen product produced from the CoNi/ZSM-5 catalyst has higher purity because no carbon formation occurs so no carbon monoxide and carbon dioxide by-products were formed [20]. Therefore, by using the CoNi/ZSM-5 catalyst obtained the highest yield of hydrogen. From this research can be concluded the best metal activity is $\mathrm{CoNi}>\mathrm{Ni}>\mathrm{Co}$. The Co/ZSM5 catalyst produces the lowest hydrogen yield because there was a carbon formation on the active site of the catalyst and catalyst sintering [1, 2]. By the coke formation on the surface of the catalyst, it can trigger the formation of carbon dioxide and carbon monoxide so the hydrogen yield becomes low. 


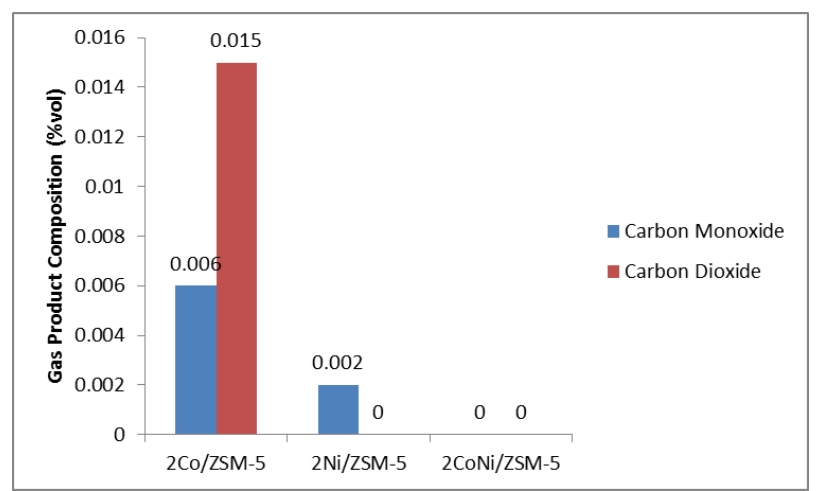

Fig. 6. Carbon monoxide and carbon dioxide product

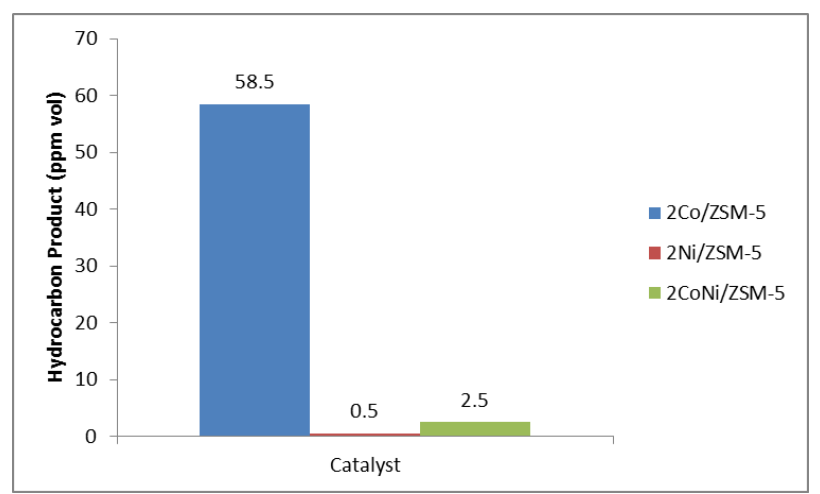

Fig. 7. Hydrocarbon product

From the results, it can be seen that the type of product formed is varies. This suggests that the type of metal may affect the reaction that occurs in the steam reforming process. Glycerol steam reforming by used nickel metal produces $\mathrm{H}_{2}, \mathrm{CO}$ and hydrocarbon, on the other hand cobalt metal produces $\mathrm{H}_{2}, \mathrm{CO}, \mathrm{CO}_{2}$ and hydrocarbon. By combined nickel and cobalt metals only produces $\mathrm{H}_{2}$ and hydrocarbon. The used of cobalt metal produced the highest $\mathrm{CO}_{2}$ and $\mathrm{CO}$. Using a cobalt metal will produce $\mathrm{CO}_{2}$ and $\mathrm{CO}$ at the beginning of the reaction (for 2 hours), after that there will decrease in $\mathrm{CO}_{2}$ and $\mathrm{CO}$ production as $\mathrm{H}_{2}$ production increases [21]. The use of nickel and cobalt metal combinations did not produce $\mathrm{CO}_{2}$ and $\mathrm{CO}$. This is because by doing a combination of metal nickel and cobalt can reduce carbon formation [20].

\section{Conclusion}

Crystallinity of ZSM-5 synthesis can improve by recalcination after catalyst impregnation because calcination can reduce the impurity of the catalyst and improve the crystal formation. The XRD characterization results showed that the Co/ZSM-5 catalyst had a crystallinity of $78.69 \%$, the Ni/ZSM-5 catalyst had $70.04 \%$ crystallinity and the CoNi/ZSM-5 catalyst had $76.99 \%$ crystallinity. But, the metals did not totally attach in the catalyst surface. It caused by the low interaction between metals and support due to imprecise calcining temperatures. Catalytic testing on hydrogen production showed that the CoNi/ZSM-5 catalyst produced the highest hydrogen concentration of $1,756.33$ ppm while the Ni/Zeolite catalyst produce $1,240 \mathrm{ppm}$ and the Co/ZSM-5 catalyst produce $491 \mathrm{ppm}$.

\section{References}

1. M. Menor, S. Sayas, A. Chica, Fuel 193, 351-358 (2017)

2. N. D. Charisiou, G. Siakavelas, K. N. Papageridis, A. Baklavaridis, L. Tzounis, K. Polychronopoulou, M. A. Goula, International Journal of Hydrogen Energy 42, 13039-13060 (2017)

3. S. Adhikari, S. D. Fernando, A. Haryanto, Energy Conversion and Management 50, 2600-2604 (2009)

4. L. Pastor-Pérez, A. Sepúlveda-Escribano, Applied Catalysis A: General 529, 118-126 (2016)

5. S. Adhikari, S. D. Fernando, A. Haryanto, Renewable Energy 33, 1097-1100 (2008)

6. D. H. Chun, J. C. Park, S. Y. Hong, J. T. Lim, C. S. Kim, H-T Lee, J-I Yang, S. J. Hung, H. Jung, Journal of Catalysis 317, 135-143 (2014)

7. Y. Vafaeian, M. Haghighi, S. Aghamohammadi, Energy Conversion and Management 76, 1093-1103 (2013)

8. van der Gaag, Technische Universiteit Delft (1987)

9. J. Weitkamp, Solid State Ionics 131, 175-188 (2000)

10. S. Abbasian, M. Taghizadeh, International Journal Nanoscience Nanotechnology 10 (3), 171-180 (2014)

11. J. Li, S. Liu, H. Zhang, E. Lu, P. Ren, J. Ren, Chinese Journal of Catalysis 37, 308-315 (2016).

12. N. H. Zamzuri, R. Mat, N. A. S. Amin, A. TalebianKiakalaieh, International Journal of Hydrogen Energy xxx, 1-12 (2016)

13. M. Yurdakul, N. Ayas, K. Bizkarra, M. El Doukkali, J. F. Cambra, International Journal of Hydrogen Energy 41, 8084-8091 (2016)

14. F. Rahmani, M. Haghighi, Y. Vafaeian, P. Estifaee, Journal of Power Sources 272, 816-827 (2014)

15. J. Majewska, B. Michalkiewicz, International Journal of Hydrogen Energy 41, 8668-8678 (2016)

16. B. Latourette, Le Raincy, C. Magnier, US Patent 4,891,199, (1990)

17. W. Widayat, A. N. Annisa, AIP Conference Proceedings 1904, 020061 (2017)

18. W. B. Widayatno, IOP Conf. Series: Journal of Physics: Conf. Series 817, (2017)

19. W. Widayat, A. N. Annisa, IOP Conf. Series: Materials Science and Engineering 214, 012032 (2017)

20. W. Nabgan, T. A. Tuan Abdullah, R. Mat, B. Nabgan, S. Triwahyono, A. Ripin, Applied Catalysis A: General 527, 161-170 (2016)

21. E. A. Sanchez, R. A. Comelli, International Journal of Hydrogen Energy 39, 8650-8655 (2014) 